\title{
CDISC SDTM Model Version 1.3
}

National Cancer Institute

\section{Source}

National Cancer Institute. CDISC SDTM Model Version 1.3. NCI Thesaurus. Code C161427.

The 1.3 version of the CDISC Study Data Tabulation Model (SDT M). 